\title{
Summary code for ocular herpes simplex
}

\author{
JOHN MCKINNON*, JAMES McGILL†, AND BARRIE R. JONES \\ From the Department of Clinical Ophthalmology, Institute of Ophthalmology, \\ Moorfields Eye Hospital, London
}

Herpes simplex virus is a major cause of serious eye disease. Despite advances in antiviral therapy many patients experience exacerbations of the disease with progressive deterioration in their condition requiring frequent and long-continued ophthalmic attention. The resulting morbidity and loss of work constitutes a major social and economic disruption.

The character of herpetic disease may change in different directions in different patients over a period of time. Many patterns of disease are possible; but at present there is no way of predicting which patients presenting with dendritic ulceration are at particular risk of developing disciform keratitis, recurrent ulceration, corneal abscess formation, or herpetic uveitis.

The sequential pattern of herpetic disease is important in assessment of the individual patient and in determining correct management at each point: it probably also has prognostic and epidemiological significance and may be related to the type of herpes virus or even to strain differences in the agent.

The complexity and diversity of possible sequences and combinations of events have hitherto made it difficult to comprehend the entire historical pattern of each patient's case, and exceedingly difficult to communicate a grasp of each case to other clinicians, or to analyse large-scale data for the existence of sequential patterns.

To overcome these difficulties in assessment and obstacles to communication we have devised a simple coding of the main morphological variants of herpetic disease, its treatment and complications. This code makes it easy to maintain a progressive summary of each case and greatly facilitates the rapid evaluation of essential data, at each decisionmaking point during management. Furthermore, it offers considerable facility in recording, analysing, and communicating the complex historical data to others.

*Present address: c/o Public Hospital, Nelson, New Zealand †Southampton Eye Hospital, Wilton Avenue, Southampton SO9 4XW

Address for reprints: Professor Barrie R. Jones, Institute of Ophthalmology, Moorfields Eye Hospital, City Road, London $\mathrm{EC}_{1} \mathrm{~V}_{2} \mathrm{PD}$

\section{Code and definitions}

A. HERPETIC LESIONS OF VARIOUS MORPHOLOGY

I. Skin

LV - typical herpetic lid vesicles

SV - typical herpetic skin vesicles occurring beyond the lids.

2. Conjunctiva

$\mathrm{HC} \quad-$ herpetic conjunctivitis An acute follicular conjunctivitis with regional lymphadenopathy. Frequently with SV (skin vesicles) or $\mathrm{LV}$ (lid vesicles) and sometimes a superficial punctate keratitis.

3. Superficial cornea

HPK - herpetic punctate keratitis

Fine granular epithelial spots which coalesce to form irregularly-shaped lesions which stain with fluorescein. Frequently with subepithelial infiltration

AU - amoeboid ulcer This is an irregularly lobulated extensive but frequently shallow ulcer with a minimum width of $2 \mathrm{~mm}$. The edges are irregular and sharply defined, and the surrounding epithelium is opaque. The base of the ulcer is yellowish-grey and the stroma shows varying degrees of infiltration and oedema. There is always an associated uveitis, often with a hypopyon. The edges of the ulcer stain with rose Bengal, and the base with fluorescein

AUS - amoeboid ulcer treated with steroids in the past week

DU - dentritic ulcer This is a characteristic zig-zag, linear, or complicated arborescent ulcer typically less than $\mathrm{I} \mathrm{mm}$ broad, with an irregular sharply 
defined edge and bead-like nodes at the end of the branches. The epithelium at the edge of the ulcer is typically opaque and swollen, and there is a varying amount of stromal haze and uveitis. The edge of the ulcer stains with rose Bengal, while the ulcer itself stains with fluorescein

DUS - dendritic ulcer treated with steroids in the past week

DURC - dendritic ulcer, recrudescent A recrudescent ulcer is one that reappears at the site of a previous ulcer within 14 days of healing

DURR - dendritic ulcer, recurrent A recurrent ulcer is one that appears more than 14 days after healing of a previous ulcer

MAU - herpetic marginal ulcer A round, oval, or irregular ulcer near the limbus, the edges of which resemble those of dendritic or amoeboid ulcers. It is normally associated with considerable stromal infiltrate and conjunctival hyperaemia which does not resemble in history or appearance a 'straphylococcal marginal ulcer' and which reponds to antiviral agents

MHU - metaherpetic ulcer An indolent round or oval ulcer with smooth sloping borders that do not stain with rose Bengal, occurring in a hypoaesthetic cornea overlying an area of stromal disease. There is a past history of herpetic disease.

Virus cultures are typically ne
LU - linear ulcer
A non-arborescent straight or A non-arborescent straight or
curved ulcer staining brightly with rose Bengal.

\section{Corneal stroma, uvea and sclera}

$\begin{array}{ll}\text { DK - } & \text { disciform keratitis (herpetic) } \\ \text { A central localized disc-shaped } \\ \text { stromal keratitis occurring typically } \\ \text { after superficial herpetic ulceration, } \\ \text { or as a primary event in the absence } \\ \text { of other systemic disease such as } \\ \text { zoster, varicella, vaccinia, or mumps. } \\ \text { The associated anterior uveitis may } \\ \text { be very mild or severe } \\ \text { DKU - disciform kerato-uveitis } \\ \text { Disciform keratitis with more than } \\ \text { I+ flare and } \mathrm{I}+\text { cells in the anterior } \\ \text { chamber }\end{array}$

HSK - herpetic stromal keratitis

A generalized or irregular non-discshaped deep keratitis almost always following herpetic ulceration. It is usually eccentrically sited in the cornea but may be very extensive. Deep stromal vascularization frequently develops

HSKU - herpetic stromal kerato-uveitis Herpetic stromal keratitis with more than $\mathbf{I}+$ cells and $I+$ flare in the anterior chamber

HCA - herpetic corneal abscess Dense opaque white or yellowish infiltrate after herpetic stromal keratitis or disciform keratitis

HU - herpetic uveitis Anterior uveitis, often severe, occurring in an eye with a history of past herpetic disease but currently no active keratitis

HSC - herpetic episcleritis or scleritis Scleral or episcleral inflammation occurring in sectional or generalized pattern in association with or following known, and active, herpetic kerato-uveitis.

\section{Associated conditions}

\begin{tabular}{|c|c|}
\hline IOP & $\begin{array}{l}\text { - intraocular pressure above } 30 \mathrm{mmHg} \\
\text { during an episode of herpetic } \\
\text { disease }\end{array}$ \\
\hline $\mathrm{DE}$ & - dry eye \\
\hline & $\begin{array}{l}\text { Diminution of aqueous tear } \\
\text { production, frequently associated } \\
\text { with drug toxicity (McGill, } \\
\text { Williams, McKinnon, Holt-Wilson, } \\
\text { and Jones, 1974) }\end{array}$ \\
\hline CAT & $\begin{array}{l}\text { - cataract } \\
\text { Secondary cataract after episodes of } \\
\text { of herpetic kerato-uveitis }\end{array}$ \\
\hline AMB & $\begin{array}{l}\text { amblyopia } \\
\text { Amblyopia after herpetic corneal } \\
\text { disease in childhood }\end{array}$ \\
\hline FK & $\begin{array}{l}\text { - filamentary keratopathy } \\
\text { Epithelial filaments after herpetic } \\
\text { corneal disease }\end{array}$ \\
\hline PDT & $\begin{array}{l}\text { - presumed drug toxicity } \\
\text { Presumed drug side-effects (for } \\
\text { example, cataract) not otherwise } \\
\text { categorized }\end{array}$ \\
\hline MIS & $\begin{array}{l}\text { miscellaneous } \\
\text { Any ocular sign not otherwise } \\
\text { categorized which is thought to be } \\
\text { due to herpetic infection (for } \\
\text { example, iris atrophy). }\end{array}$ \\
\hline
\end{tabular}


B. MANAGEMENT

I. Drug treatment

$\mathrm{S} \quad$ - steroid

Treated with topical steroids

IDU - treated with Idoxuridine (IDU)

IDUT - IDU toxicity

An eye treated with IDU, usually for at least ro days (but the period can be shorter if treatment is very intensive or if IDU treatment has been used on previous occasions), which demonstrates one or more of the following (McGill and others, 1974; Patterson and Jones, 1967): lid - ptosis lid margin - keratinization

- rounded edge

- Meibomian orifice occlusion

punctum - narrowing or occlusion

limbus - follicles or oedema conjunctiva - punctate epithelial disease, characteristically in the interpalpebral fissure, staining with rose Bengal

cornea - punctate epithelial keratopathy

- flaking opaque epithelium, staining with rose Bengal

- microcysts, some staining with fluorescein

- sub-epithelial opacification and vascularization (changes aggregate in a curved or linear fashion with whorl-shaped patterns of epithelial keratopathy)

indolent corneal ulcer - developing usually from a linear pattern of punctate keratopathy. It may thus somewhat resemble a dendritic ulcer and may progress to resemble a metaherpetic ulcer.

There is marked associated punctate epithelial keratopathy.
IDUR - IDU resistance

An ulcer adequately treated with IDU which:

I. is getting worse after 4 days, or is static after 7 days, or is changing shape but not healing by Io days

2. shows no sign of IDU toxicity

3. has no significant underlying active infiltrate

IDUH - IDU hypersensitivity Contact dermatitis of the lids after IDU application to the eye

$\mathrm{F}_{3} \mathrm{~T}$ - treated with trifluorothymidine

$\mathrm{F}_{3} \mathrm{TT}-\mathrm{F}_{3} \mathrm{~T}$ toxicity

An eye treated with $F_{3} T$ which demonstrates one or more of the following (McGill and others, 1974): punctum - narrowing conjunctiva - punctate epithelial disease, characteristically in the interpalpebral fissure staining with rose Bengal

cornea

- punctate epithelial keratopathy

- epithelial microcysts

- epithelial oedema

(Other toxic signs may be recognized as clinical experience with $\mathrm{F}_{3} \mathrm{~T}$ grows. The time required for toxicity to develop is not yet defined)

$\mathrm{F}_{3} \mathrm{TR}-\mathrm{F}_{3} \mathrm{~T}$ resistance

An ulcer adequately treated with $\mathrm{F}_{3} \mathrm{~T}$ which:

I. is getting worse after 4 days, or is static after 7 days, or is changing shape but not healing by ro days

2. shows no sign of $\mathrm{F}_{3} \mathrm{~T}$ toxicity

3. has no significant underlying active infiltrate

$\mathrm{F}_{3} \mathrm{TH}-\mathrm{F}_{3} \mathrm{~T}$ hypersensitivity Contact dermatitis of the lids after $\mathrm{F}_{3} \mathrm{~T}$ application to the eye

AA - treated with adenine arabinoside

AAT - Ara-A toxicity An eye treated with Ara-A which demonstrates one or more of the following: conjunctiva - punctate epithelial disease, characteristically in the interpalpebral fissure, staining with rose Bengal 
cornea - puntate epithelial

(Other toxic signs may be recognized as clinical experience with Ara-A grows. The time required for toxicity to develop is not yet defined)

AAR - Ara-A resistance

An ulcer adequately treated with Ara-A which:

I. is getting worse after 4 days, or is static after 7 days, or is changing shape but not healing by 10 days

2. shows no sign of Ara-A toxicity

3. has no significant underlying active infiltrate

AAH - Ara-A hypersensitivity

Contact dermatitis of the lids after Ara-A application to the eye. (We have not recognized hypersensitivity to Ara-A to date.)

2. Physical treatment
DB
- debridement
Simple removal of the ulcerated epithelium
CA - carbolization
Removal of the ulcerated epithelium followed by application of phenol
ID
- iodization
Removal of the ulcerated epithelium followed by application of iodine
CY - cryotherapy
Application of a cryoprobe to the ulcer and surrounding area.

3. Surgery
CF - conjunctival flap
TA - tarsorrhaphy
PKP - penetrating keratoplasty
LKP - lamellar keratoplasty
AR - allograft reaction

\section{Contact lens}

SCL - 'soft' (hydrophilic) contact lens

HCL - haptic contact lens

c. CLINICAL STUdies

I. RES - research

Patients entered into clinical drug

trials or other research projects

(Designated $\mathrm{RES}_{1}, \mathrm{RES}_{2}$, etc.)

\section{Method of use of the code}

Patients with herpetic ocular disease are classified according to the code and this coded summary is recorded on the cover of their case notes.

The codes relating to each significant episode of disease or treatment are recorded on a separate line opposite the date of start and finish of treatment.

For example, Fig. I designates a patient with three significant episodes. An initial dendritic ulcer was treated with Idoxuridine. During the course of this illness kerato-uveitis developed and the patient was treated with steroids. After a further bout of kerato-uveitis a penetrating keratoplasty was performed. A dendritic ulcer developed during treatment with steroids and IDU toxicity necessitated a change of therapy to $\mathrm{F}_{3} \mathrm{~T}$, with the ulcer finally resolving.

Each patient's codes are recorded on punch cards. Fig. 2 shows a punch card for the above patient. Punch cards are updated from line to line, thus the codes for the first two episodes of disease have been transferred as indicated on the right-hand column of Fig. I.

On the reverse side of each punch card code data are recorded in the same manner as Fig. I. Thus all code information relevant to a patient is recorded in one place. Retrieval of data is simplified and the system allows for future elucidation of associated features or patterns.

\section{Discussion}

A continuing problem for ophthalmologists treating herpetic eye disease is the difficulty in relating

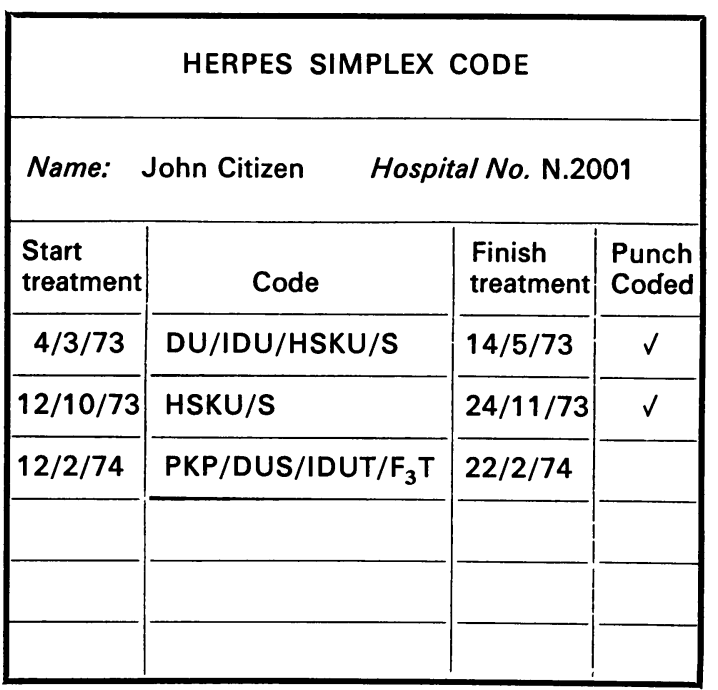

FIG. I Herpes simplex code 


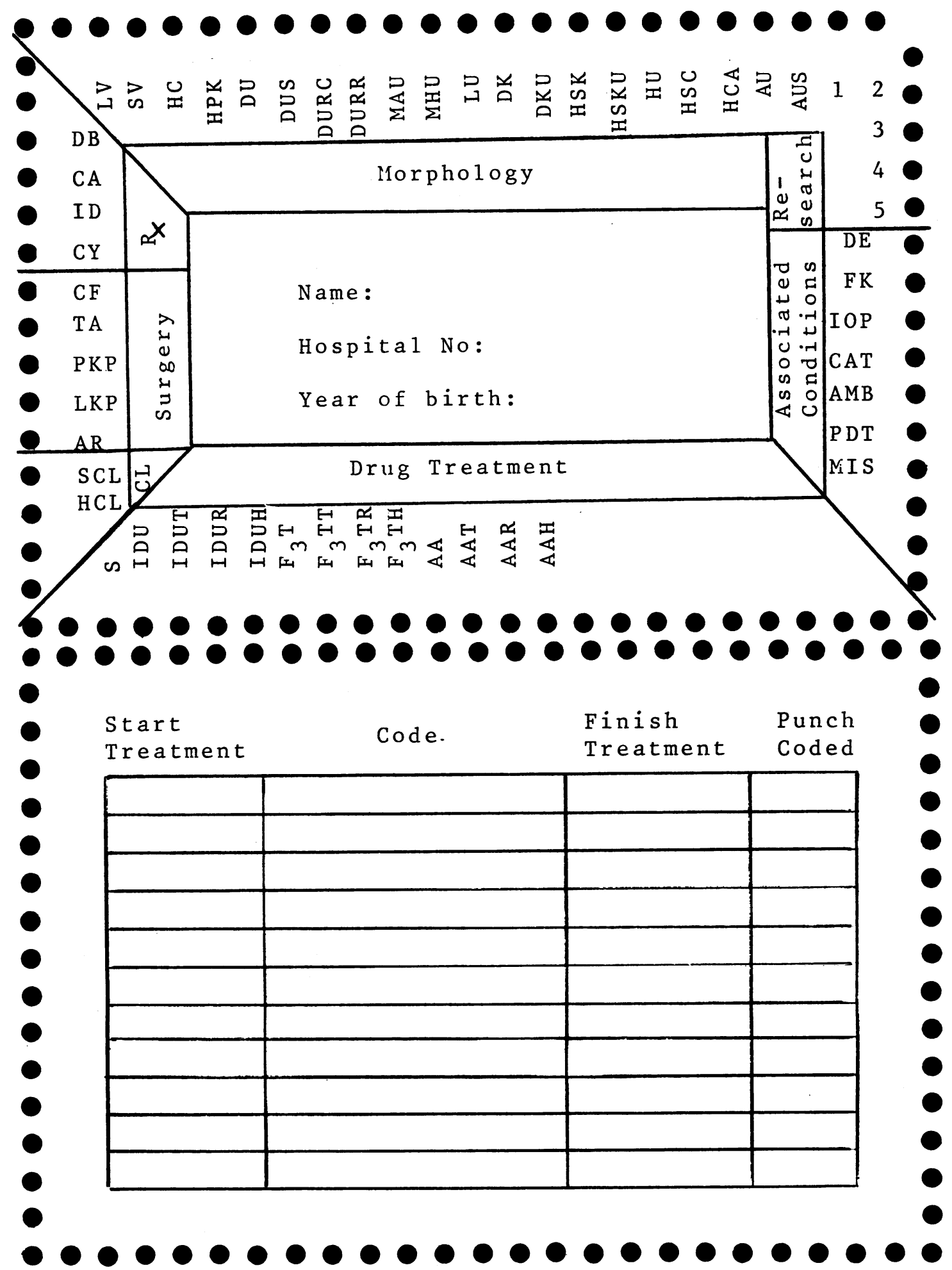

FIG. 2 Two sides of punch card recording clinical features, complications, treatment, and prognosis of herpes simplex eye disease 


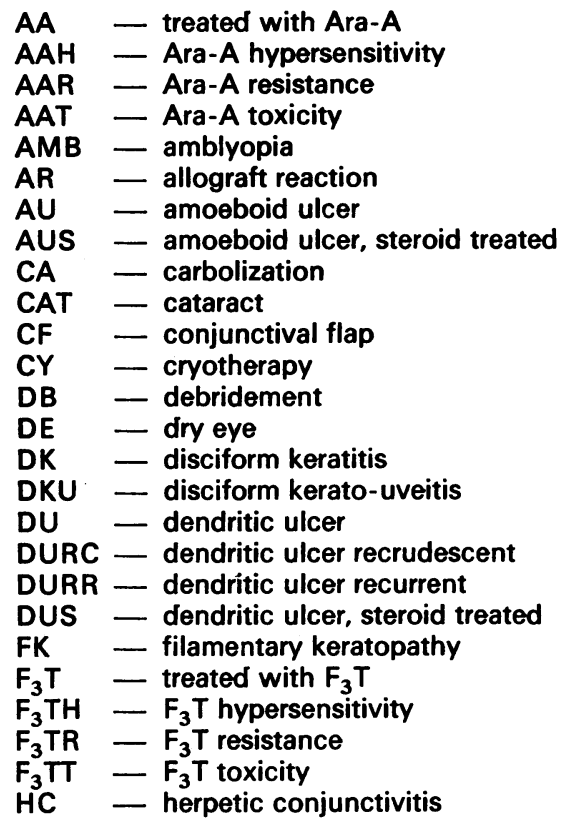

HCA - herpetic corneal abscess
HCL - haptic contact lens
HPK - herpetic punctate keratitis
HSC - herpetic episcleritis or scleritis
HSK - herpetic stromal keratitis
HSKU - herpetic stromal kerato-uveitis
HU - herpetic uveitis
ID - iodization
IDU - treated with IDU
IDUH - IDU hypersensitivity
IDUR - IDU resistance
IDUT - IDU toxicity
IOP - raised intraocular pressure
LKP - lamellar keratoplasty
LU - linear ulcer
LV - lid vesicles
MAU - marginal ulcer
MHU - metaherpetic ulcer
MIS - miscellaneous
PDT - presumed drug toxicity
PKP - penetrating keratoplasty
RES - research
S - treated with steroid
SCL - soft' contact lens
SV - skin vesicles
TA - tarsorrhaphy

FIG. 3 Code summary in alphabetical order

significant events in the patient's past to his current problems. This difficulty is compounded when several clinicians are caring for the same patient.

Since the introduction of our coding system in a busy clinic for virus diseases, all clinicians concerned have been impressed by the way in which it facilitates clinical assessment of cases. A glance at the patient's code summary allows one to grasp important features of his past history and present situation, even if the patient is unfamiliar to the ophthalmologist.

We have the impression that a patient's history influences the way in which a new episode of disease presents, progresses, and responds to treatment. Use of this code and the punch card or computerized cross-reference system should help to elucidate possible patterns in evolution of disease, correlations in response to therapy, or otherwise unnoticed possible adverse effects of therapy.

\section{Summary}

A code for herpetic eye disease is presented. This simplifies the management of individual patients, and the up-to-date code summary of each case is easily maintained thus facilitating assessment of interrelating factors. It is suggested that the pattern of herpetic eye disease may have prognostic and epidemiological significance. This system has simplified retrieval of such data.

The assistance of Mrs Jane Field in preparation of this manuscript is gratefully acknowledged.

\section{References}

MCGill, J. I., Williams, H. P., MCKinnon, J. R., holt-Wilson, A. D., and JONES, B. R. (1974) Trans. ophthal. Soc.

U.K., 94, 542

PATterson, A., and JONES, B. R. (1967) Ibid., 87, 59 